\title{
'Decarbonising' UK industry: towards a cleaner economy
}

Samuel J. G. Cooper

Research Associate, Department of Mechanical Engineering, University of Bath, Bath, UK (Orcid:0000-0002-3229-3026)

Reducing industrial energy demand and improving resource efficiency could make a substantial contribution towards the UK government's goal of achieving $\mathbf{8 0} \%$ reduction in carbon dioxide emissions by 2050 , while simultaneously improving productivity and creating employment opportunities. In this context, the government released its 'Clean Growth Strategy' in October 2017, although it has a number of limitations. The associated technology roadmaps exhibit quite large uncertainties, and reducing carbon dioxide emissions over the long term will depend critically on the adoption of a small number of key technologies, alongside the 'decarbonisation' of electricity supply. 'Circular economy' interventions have the potential to make significant energy savings that are complementary to other energy-efficiency measures. However, the task for both industrial and policy decision makers will still be challenging.

\section{Introduction: the climate change challenge}

Human development is underpinned by energy sources of various kinds that heat, power and transport its citizens in their everyday life. However, while energy supplies and technologies underscore continued economic development, they also give rise to unwanted side effects. Arguably, the principal environmental burden emanating from the energy sector is the prospect of global warming due to an enhanced greenhouse effect induced by fossil fuel combustion (Hammond, 2000; IPCC, 2013). Carbon dioxide is the principal 'greenhouse gas' (GHG) having an atmospheric residence time of about 100 years (Hammond, 2000). This mainly arises from the combustion of fossil fuels, coal and natural gas in power stations and petroleum in motor vehicles, as well as for heating in buildings and industrial processes. Changes in atmospheric concentrations of GHGs affect the energy balance of the global climate system. Human activities have led to quite dramatic increases since 1950 in atmospheric carbon dioxide; concentrations have risen from $330 \mathrm{ppm}$ in 1975 to about 430 ppm currently (IPCC, 2013). The most recent (2013) scientific assessment by the Intergovernmental Panel on Climate Change (IPCC) asserts that it is 'extremely likely' that humans are the dominant influence on the observed global warming since the mid-twentieth century. The 2015 Paris Agreement on climate change aims to keep temperatures 'well below $2^{\circ} \mathrm{C}$ above pre-industrial levels and to pursue efforts to limit the temperature increase to $1 \cdot 5^{\circ} \mathrm{C}$ above pre-industrial levels' (Ares and Hirst, 2015: p. 18). The $2^{\circ} \mathrm{C}$ figure is broadly consistent with the 2050 carbon dioxide emissions target established in the United Kingdom of Great Britain and Northern Ireland (UK). However, 'bottom-up' national pledges received in connection with the Paris Conference for GHG mitigation efforts are expected to result in a warming of around $2.7^{\circ} \mathrm{C}$ (Ares and Hirst, 2015). Therefore, the world still faces a significant challenge of reducing GHG emissions further in order to bring global warming into line with the aspirations in the Paris Agreement.

The evolution of modern industrialised society has been interwoven with discoveries of sources and uses of energy (Hammond and Pearson, 2017), especially the exploitation of fossil fuel resource stocks, the assembly of energy infrastructures, and the development of end-use technologies and practices. With its coal reserves, ports and engineering skills, Britain lay at the heart of the first industrial revolution. Nowadays, while energy supplies underpin continued economic development, this fossil fuel dependence exposes the UK to major risks: supply and resource insecurities; increasing costs of energy supply; and damage to the quality and longer-term viability of the biosphere. The British government has therefore introduced a bold, legally binding target of reducing the nation's carbon dioxide emissions overall by $80 \%$ by 2050 in comparison to a 1990 baseline (DECC, 2011) in their Climate Change Act 2008. This initiative led the way globally, and subsequent pathways for achieving such levels of GHG savings are now known as 'deep decarbonisation' in much of the industrialised world (see e.g. Åhman et al., 2016; Bataille et al., 2018; Wesseling et al., 2017). The British government's independent Committee on Climate Change (CCC), established under the 2008 Climate Change Act, has advocated deep cuts in power sector operational emissions through the 2020s (CCC, 2015), with the UK electricity generation being largely 'decarbonised' by 2030-2040. In recommending 
the fifth 'carbon budget' for the period 2028-2032, they proposed a 57\% fall in GHG emissions below 1990 levels by 2032. Achieving these carbon dioxide reduction targets will require a challenging transition in Britain's systems for producing, delivering and using energy that is not only 'low carbon', but also secure and affordable; thus resolving three components of the so-called energy policy 'trilemma' (Hammond and Pearson, 2017). These GHG reductions will necessitate a radical transition towards an energy system that delivers highquality energy services through low-carbon dioxide technologies and processes, that are also secure and at competitive prices.

\section{Importance of industry in securing a clean economy}

Industry in the UK accounts for some $18 \%$ of total delivered energy and $21 \%$ of GHG emissions (BEIS, 2017; ONS, 2017) and so decarbonisation measures will be essential in order to achieve the $80 \%$ reduction target by 2050 . There are large differences between industrial sub-sectors in the end-use applications of energy, especially in terms of products manufactured, processes undertaken, and technologies employed: see Figure 1. They range from highly energy-intensive (EI) steel production and petrochemicals processing to low-energy electronics fabrication (Dyer et al., 2008). The former sector typically employs large quantities of (often high-temperature) process energy, whereas the latter tends to be dominated by energy uses associated with space heating. Around 350 separate combinations of sectors, devices and technologies can be identified (Dyer et al., 2008); each combination offers quite different prospects for energy-efficiency improvements and carbon dioxide savings, which are strongly dependent on the specific technological applications. This large variation across industry does not facilitate a cross-cutting, 'one size fits all' approach to the adaptation of new technologies in order to reduce energy demand but, rather, requires tailored solutions for separate industries (Dyer et al., 2008). Thus, it is widely recognised that of all parts of the UK economy, industry has arguably the weakest data on industrial energy use and the potential for GHG emissions reduction.

There is clearly a great need for research aimed at providing better information in support of the UK industrial strategy for policymakers, including the potential impact of fuel switching (particularly to potentially low-carbon dioxide energy carriers, notably electricity), as well as the identification of difficult sectors/processes to reduce the carbon dioxide emissions and areas where investment could be targeted most effectively. GHG emissions are not the only environmental burden that stems from industrial activities. However, 'carbon footprints' have become the 'currency' of debate in a climateconstrained world (Cranston and Hammond, 2012). The CCC views industrial decarbonisation as a 'difficult' area in which to secure appropriate carbon dioxide savings.

\section{From industrial sectoral analysis to strategy}

The GHG emissions from the UK industry can be split by sector (Hammond, 2014) as illustrated in the pie chart presented as Figure 2. This includes emissions from energy use (including those indirectly emitted from electricity use) and process emissions. Thus, the production of cement

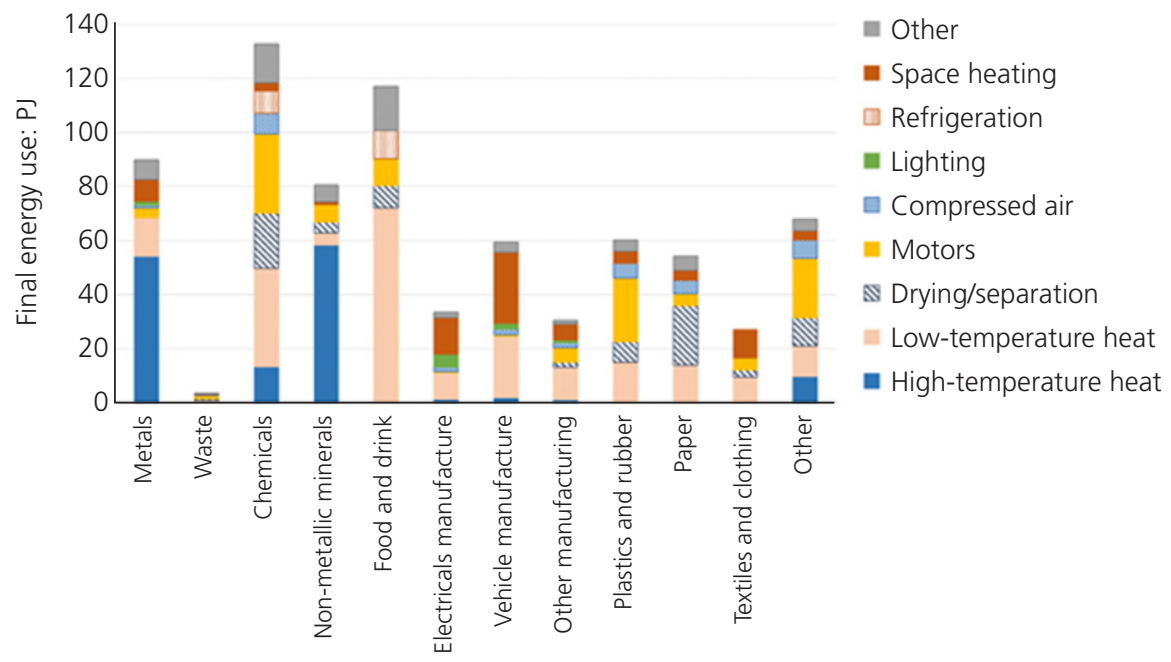

Figure 1. Final UK energy demand by industrial subsector and end-use (produced with data adapted from BEIS (2017)). A full-colour version of this figure can be found on the ICE Virtual Library (www.icevirtuallibrary.com) 


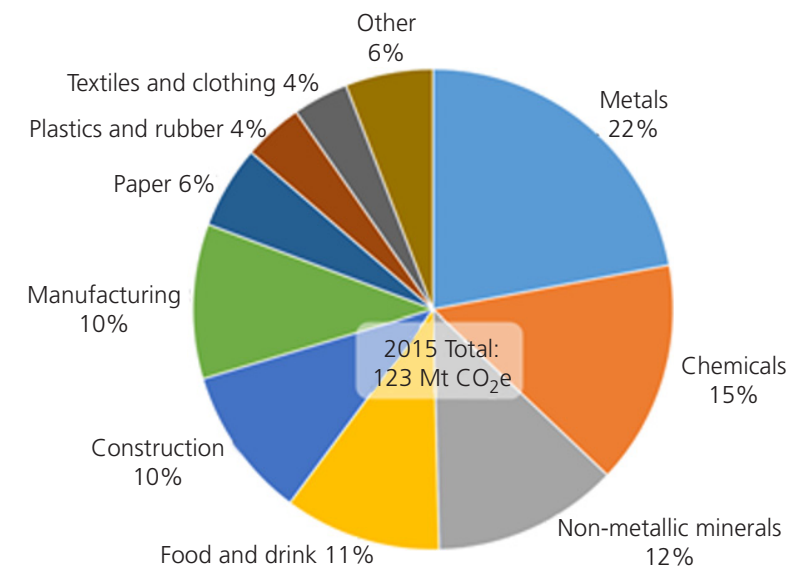

Figure 2. GHG emissions from the UK industry (produced with data adapted from BEIS (2017) and ONS (2017)). A full-colour version of this figure can be found on the ICE Virtual Library (www.icevirtuallibrary.com)

(Griffin et al., 2014, 2016; Hills et al., 2016; Li et al., 2013), for example, releases pure carbon dioxide directly into the atmosphere when calcium carbonate is heated to produce lime (calcium oxide; in a process known as 'calcining') which, in turn, requires energy input for the heating process itself (leading to additional carbon dioxide emissions upstream). Industrial sectors with significant process emissions are steel, chemicals, cement, aluminium, glass, ceramics and lime. Information on energy use, emission conversion factors and process emissions can be combined in order to determine the total emissions (Griffin et al., 2016). The 2015 data reveal that a number of sectors dominate GHG emissions from the UK industry (see again Figure 2): metals (22\%), chemicals $(15 \%)$, non-metallic minerals $(12 \%)$, food and drink $(11 \%)$, construction $(10 \%)$ and manufacturing $(10 \%)$. This suggests Pareto-like priorities for bottom-up studies of the sector (of the type analysed by Griffin et al. (2014, 2016, 2017, 2018)) with just six sub-sectors accounting for $80 \%$ of UK industrial emissions. Much of the activity in some of these sectors is due to a relatively small group of major players whose actions have a large influence on the bulk of sectoral performance. The post2008 economic recession in the UK (and globally elsewhere) resulted in the closure of some large plants, particularly aluminium smelters and steel mills. The closure of the Redcar steelworks on Teesside in late 2015 is a major example of this; being the cause of nearly half the decline in industrial GHG emissions in 2016. The long-term future of these industrial sectors, and how much capacity other plants may change in response, is clearly uncertain. The closure of major industrial facilities must be set against the background of a general economic slowdown with significant closures also seen in the cement and paper sectors since 2008 .
Reducing industrial energy demand and improving resource efficiency could make a substantial contribution towards the UK government's goal of significant $(80 \%)$ decarbonisation by 2050 (Hammond, 2014), while simultaneously improving productivity and creating employment opportunities. Both fossil fuel and process GHG emissions will need to be significantly reduced over this time frame. Ultimately, all industrial energy use and emissions result from the demand for goods and services. Energy is required at each stage in the manufacture of a product, or 'life-cycle', from raw material extraction through to the final distribution and eventual disposal. The required energy and associated GHG emissions at different points along these UK supply chains emanate from many different countries, due to the growth of globalisation. The UK government, led by its Department for Business, Energy and Industrial Strategy (BEIS), released its 'Clean Growth Strategy' (CGS) in October 2017 (HMG, 2017a), alongside seven Industrial Decarbonisation and Energy Efficiency Action Plans produced jointly with industrial partners covering different industrial sectors. Thus, the 'Action Plans' contain voluntary commitments to reduce GHG emissions, while 'maintaining international competitiveness'.

The Minister for Energy and Clean Growth (the Rt Hon Claire Perry MP) regards the CGS as a 'march on a decarbonisation pathway' for the UK economy. A novel focus of the strategy is on the notion of growing national income while cutting GHG emissions. It is argued that this will improve productivity, create 'good jobs' and enhance the earning power of employees at the same time as meeting the climate change and environmental objectives of the UK. The CGS sets out an aim to improve energy productivity by at least $20 \%$ over the period to 2030 . This will be stimulated, in part, by way of government investment of $£ 162$ million in clean growth innovation funding out to 2021 by way of a new BEIS Energy Innovation Programme, including greenhouse gas removal (GGR) technologies; much of it is earmarked for industrial carbon dioxide capture and storage (CCS). $£ 20$ million will be used to support industrial demonstrations of switching to lowcarbon dioxide fuels, while $£ 18$ million will assist with the establishment of a new industrial heat-recovery programme. Many of the proposals in the CGS will be subject to various consultations, including that on a Streamlined Energy and Carbon Reporting (SECR) framework for large businesses. Claire Perry also has an ambition to create a 'gold standard' in accelerating green finance and regulatory frameworks that will encourage new business models for the UK. BEIS will seek to monitor progress with these measures by way of a Clean Growth Inter-Ministerial Group, aided by a new metric - the emissions intensity ratio (EIR), defined in terms of GHG emissions per unit of national income. The government wants this EIR to fall by $63 \%$ between now and 2032 . Subsequently, the CGS and associated action plans were 
underpinned by the government's Industrial Strategy white paper published in November 2017 (HMG, 2017b), which has as a 'grand challenge' the aim of taking advantage of the 'global shift to clean growth' for the benefit of UK industry. The overall emphasis is on improving productivity by way of the encouragement of innovation, research and development (R\&D), and skills training. It envisages a large increase in public investment in $\mathrm{R} \& \mathrm{D}$, through an Industrial Strategy Challenge Fund (initially of $£ 275$ million), together with the commercialisation of its outputs.

\section{Weaknesses in the UK CGS}

The much-delayed publication of the CGS (HMG, 2017a), originally scheduled for 2016 (when it was known as the Emissions Reduction Plan), has been generally welcomed by both industry and civil society groups. In addition, organisations in the energy-efficiency and carbon dioxide reduction field that were set up by previous UK governments, such as the Carbon Trust and Energy Savings Trust (now independent bodies), have expressed their pleasure at the content of the CGS. The CCC also welcomed it as representing a move in the right direction. However, it voiced concern over the vagueness of many of the suggested climate change mitigation actions and the potential reliance by the UK government on what they regard as 'flexibilities' in the Climate Change Act 2008 in order to meet the requirements of the fifth carbon budget targets (CCC, 2015). The CCC views such flexibilities as 'banking and borrowing', whereas it believes that future carbon budgets out to 2032 at least should be met by way of domestic UK action (CCC, 2018). It regards banking emissions from the overachievement in emissions reductions under the second and third carbon budgets as a retrograde step. It could put at risk the UK commitment to achieving the goals of the Paris Agreement, which include a much greater challenge of moving towards $1.5^{\circ} \mathrm{C}$ global warming than the $2^{\circ} \mathrm{C}$ target in place when the $\mathrm{CCC}$ originally recommended its fifth carbon budget goals. It would also undermine investor confidence in the development of innovative technologies, such as CCS or carbon capture and utilisation (CCU). Indeed, many antagonists, not just those in the CCS community, have expressed disappointment at the rather modest ongoing support promised for GGR technologies. There is a clear need to explore whether CCU can be taken beyond a few niche products.

\section{Technological options for industrial decarbonisation}

There is significant potential to secure efficiency gains in UK industry, including those associated with the use of heat and with improvements in processing. A series of studies at the University of Bath found that currently available technologies are likely to lead to further, short-term energy and GHG emissions savings in industry, but that the prospects for the commercial exploitation of innovative (the so-called 'disruptive') technologies by mid-twenty-first century are far more speculative (Griffin et al., 2014, 2016, 2017, 2018). There are a number of non-technological barriers to the take-up of such technologies (Griffin et al., 2016). Consequently, the transition pathways to a low-carbon dioxide future in UK industry by 2050 will exhibit large uncertainties. The attainment of significant falls in GHG emissions over this period will depend critically on the adoption of a limited number of key technologies as follows.

Energy-efficiency and heat-recovery techniques (including improved thermal insulation of industrial buildings, furnaces and process equipment; energy-efficient lighting; modern heat exchangers; combined heat and power (CHP) plants (particularly biomass-CHP); and industrial heat pumps).

- Fuel switching; principally to biomass/bioenergy (but potentially to hydrogen $\left(\mathrm{H}_{2}\right)$ ).

- CCU/CCS; although the CCS and CCU research communities in the UK have quite divergent views on the potential economics and take-up of these technologies. Bioenergy CCS (or BECCS) potentially gives rise to advantageous 'negative emissions'. The development of CCS clusters, or GHG pipeline networks, between the 'carbon capture' systems of electricity generators and industrial process plants, and offshore storage facilities, is obviously a key requirement.

- Decarbonisation of electricity supply; facilitating, for example, low-carbon dioxide electrification of heating for both industrial buildings and processes.

The suitability of these measures depends, in large part, on the nature of the industrial sector concerned. Energy-efficiency measures are normally economic (i.e. they use less energy in the most cost-effective manner) and have a relatively short payback period. Significant potential exists for reusing surplus (or waste) heat from industrial processes, particularly at low temperatures by way of the utilisation of heat exchangers (Cooper et al., 2016; Hammond and Norman, 2014). Such heat could also be converted to electricity by employing innovative technologies, like organic Rankine cycle (ORC) devices (Chen et al., 2016). These technologies exist in commercial applications, but are not well established. Support for their development and installation is therefore required in order to increase their use. CHP plants are an important and available option at a large, industrial scale. Take-up is already encouraging in many industrial sub-sectors. In contrast, heat pumps are technologies which, at both a small (domestic) and industrial scale, have been slow to take off. International research groups, such as the Energy Research Centre of the Netherlands $(\mathrm{ECN})$, are working actively in this area. 
Bioenergy can be produced from either biomass (any purposegrown material, such as crops, forestry or algae) or biogenic waste (including household, food and commercial waste, agricultural or forestry waste). Thus, bioenergy systems are largely available technologies, limited mainly by restrictions on indigenous, sustainable biomass and biogenic waste resources, delivery and social factors. Sustainable bioenergy is a renewable resource that is often low-carbon dioxide and potentially gives rise to 'carbon sinks' or 'negative emissions' when coupled to CCS facilities. BECCS is likely to have an important role in securing the $1.5^{\circ} \mathrm{C}$ global warming target under the 2015 Paris Agreement on climate change. It will require continuing research, development and demonstration (RD\&D) as it is typically regarded as an unproven technology at full scale. There are currently just six operational pilot-scale BECCS projects worldwide; with another 12 in the planning or evaluation stage. The potential for generating a modern 'bioeconomy' is recognised in industrial sectors such as chemicals and the paper products industry. However, virtually no bioenergy is currently used in the chemicals sector, except for the production of bio-hydrogen. There is substantial prospect for producing high-value chemicals from biomass feedstock in state-of-the-art biorefineries (Griffin et al., 2017). They will yield substitutes to many of the chemicals and plastics presently based on fossil-fuel feedstocks. In addition to these options, there is scope in some industrial sectors (such as pulp and paper (Griffin et al., 2018)) for the adoption of demandside flexibility (DSF) techniques, whereby levels of electricity demand are increased, reduced or shifted, and on-site energy storage then enables the optimisation of electricity usage. This also has major advantages in the context of an energy infrastructure designed to meet occasional peak demands.

Many industrialists view $\mathrm{CCS} / \mathrm{CCU}$ as being costly technologies that will probably continue to be prohibitively expensive out to 2050 (Hammond, 2013). Possible exceptions to that are sectors with large processing facilities, such as chemicals and steel plants. The CCU community typically argues that the processing of usable products from carbon dioxide emissions adds economic value to offset the costs of 'carbon capture', whereas CCS (unless used in connection with enhanced oil or gas recovery) is a high-cost process. (Some early work by the late Dutch physical chemist Willem van Gool in the mid-1970s proposed the capture of carbon dioxide emissions and their use as a feedstock in the production of durable consumer goods by way of chemical methods (Hammond, 2007; Van Gool, 1975).) The clustering of GHG networks between electricity generators and industrial process plants, together with their coupling to offshore storage facilities, is an important requirement for the practical adoption of CCS (and possibly CCU) in the UK and elsewhere (Griffin et al., 2016). This requires ongoing RD\&D as part of a collaborative programme with the manufacturing/processing sectors and electricity and gas supply utilities. Nevertheless, all steam crackers and ammonia plant are situated within potential UK CCS cluster regions (Griffin et al., 2017); see, for example, Figure 3. The UK government (see e.g. DECC, 2012) has from time to time aimed at developing a sustainable CCS industry that might capture emissions from clusters of industrial process plants and electricity power stations linked together by a pipeline network transporting carbon dioxide to suitable storage sites offshore (EE, 2010; Griffin et al., 2016). These CCS clusters hold out the prospect of providing integrated carbon dioxide pipeline networks, which could be formed of multiple branches that link individual sources to a common hub and main pipeline, thereby sharing CCS infrastructure (DECC, 2012). Such integrated pipelines could considerably decrease the costs of transport, particularly from smaller carbon dioxide sources. In addition, CCS clusters could potentially reduce significantly the disruption and transaction costs, as well as investment risks (Hammond, 2013), associated with permitting and installing multiple point-topoint pipeline networks (EE, 2010). Indeed, carbon dioxide transport and storage costs present a greater hurdle than that associated with capture costs themselves (Griffin et al., 2016). However, there are major challenges in commercially financing carbon dioxide pipelines (Hammond, 2013) that are likely to be over-sized in the period before CCS becomes a mature, commercial technology (EE, 2010). Cluster regions of industrial activities have been identified for storage under both the North Sea (EE, 2010) and the north-east part of the Irish Sea (DECC, 2012). The distribution of these carbon dioxide point sources and potential UK CCS cluster regions are illustrated in Figure 3 (adapted from Griffin et al. (2016)). They are principally along the east coast of the UK adjacent to depleted oil and gas fields in the North Sea: the Firth of Forth in Scotland, Teesside in the north-east of England, and the Humber and Thames estuaries on the east coast of England. The main industrial area in Wales (and one of the largest agglomerations in the UK) is on its south coast, but does not have appropriate carbon dioxide storage locations in its vicinity - that is, beneath the Bristol Channel. In contrast, the more modest industrial area in the north-east of Wales could make use of the adjacent Liverpool-Manchester CCS cluster with storage capacity in the Irish Sea. Nevertheless, pipeline technology for building a carbon dioxide transport network is ready to be rolled out, and the UK already has preliminary plans for at least two large carbon dioxide transport hubs (see again Figure 3), for example, at the St Fergus gas terminal in central Scotland, with its multiple 'pipelines' taking carbon dioxide by way of Peterhead harbour out to North Sea storage sites (by way of the Acorn CCS Project that is part of the 'Advancing CCS Technologies' (ACT) Programme; funded by the European Union (EU)), and the corresponding Teesside Collective CCS Project. Indeed, the UK government is 


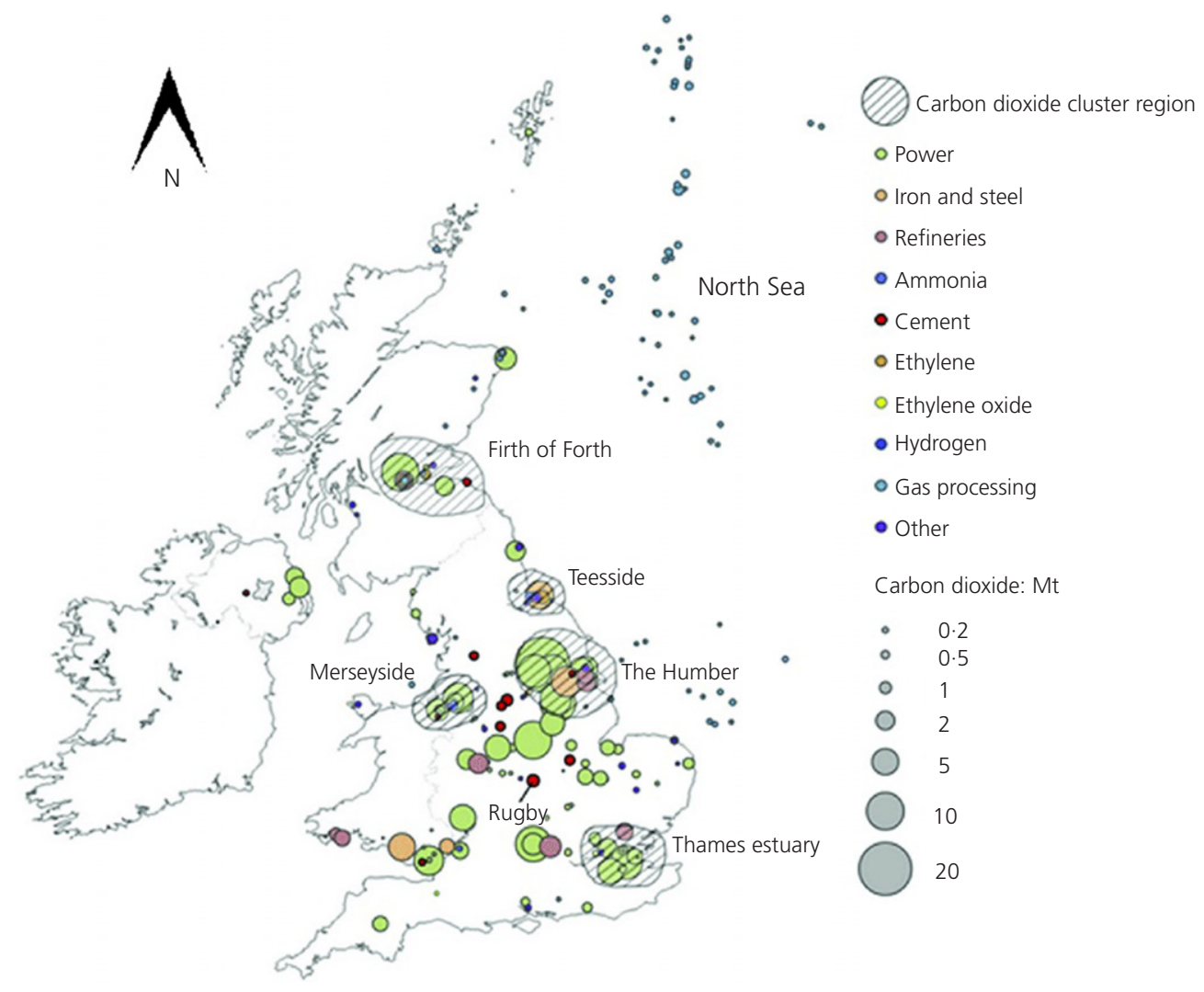

Figure 3. Distribution of carbon dioxide point sources and CCS cluster regions in the UK (source: Griffin et al. (2016)). A full-colour version of this figure can be found on the ICE Virtual Library (www.icevirtuallibrary.com)

committed to the support of ongoing $\mathrm{CCS} / \mathrm{CCU}$ initiatives to test the potential for the development of industrial carbon dioxide pipeline clusters on Teesside and Merseyside, in South Wales and at Grangemouth as set out in its CGS (HMG, 2017a). Roddy (2012) has studied the practical issues involved in building a carbon dioxide pipeline network in the north-east of England (see again Figure 3). He suggests that a medium-sized network is likely to be economic at estimated future carbon dioxide prices. Such clustering is viewed as one of the CCS enabling factors by BEIS in the UK (HMG, 2017a).

\section{Towards a 'circular economy'}

Circular economy (CE) interventions - sometimes termed 'value chain collaboration' by BEIS - seek to reorganise products and services to improve resource use efficiency by designing out waste, recycling and reusing materials, and thereby minimising their negative side effects. Arguably, measures of this type will reduce product consumption sufficiently to achieve sustainable development goals and mitigate climate change. Such strategies will slow throughput of materials across the economy. The approach has also achieved prominence by way of the European Commission's 'Circular Economy Package' (EC, 2015). A reassignment of material flows within the $\mathrm{CE}$ has been conceptualised by the EU (EC, 2015), and is represented schematically in Figure 4. The concept has been championed by the Ellen MacArthur Foundation, which presents it more broadly in terms of expanding the 'waste hierarchy', 'circling longer' or enabling cascaded use (EMAF, 2015). The Foundation claims that these approaches increase employment, more effectively capture value, mitigate exposure to supply chain and market risks, and better develop customer relationships. Such approaches can be viewed as an alternative to the conventional linear 'takemake-consume-dispose' economic model (see Figure 4). Extended producer responsibility (EPR) is one of various $\mathrm{CE}$ policy interventions under which producers are given a significant responsibility for the end-of-life treatment or disposal of post-consumer products. This effectively requires producers to internalise the cost of some of the market 'externalities' (Hammond and Winnett, 2006) associated with their products. 


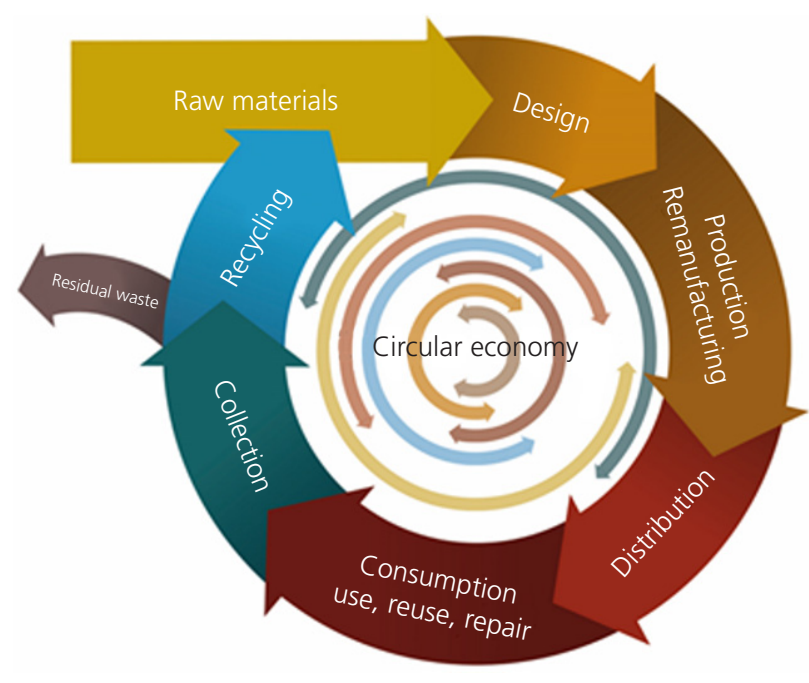

Figure 4. Schematic representation of material flows in a more CE (source: EC (2015))

Consumers are encouraged to separate and recycle products such as used batteries and light bulbs. If producers make it easy to recycle such items, then consumers are much more likely to do so. In the UK only four EPR systems have currently been adopted with stimulus from the EU, which cover packaging, waste electrical and electronic equipment (WEEE), end-of-life vehicles (ELVs) and batteries. Even emerging rechargeable batteries will eventually need to be recycled (see e.g. Hammond and Hazeldine, 2015). A high level of embodied energy and carbon dioxide in goods and services - fuel use and GHG emissions that arise upstream of the point of production or use - are traded internationally. This consequently means that much of the reduction in energy use and GHG emissions that results from applying CE interventions will occur outside of the country in which they are utilised. Similarly, energy demand due to exports from a region is likely to decrease due to $\mathrm{CE}$ approaches applied elsewhere. The development of an international accounting system for embodied carbon dioxide emissions that takes account of these global flows would no doubt help countries work together to reduce global warming.

The implications of $\mathrm{CE}$ interventions have recently been studied analytically by Cooper et al. (2017a). They collated evidence on specific quantifiable approaches, calculated their combined overall supply chain impacts by way of input-output analysis and then used thermodynamic analysis to investigate the aggregate effects. Several potential CE interventions were examined in a global context, across the EU-27, and in the UK. They were found to have similar overall potential to save energy as industrial energy-efficiency measures. Some CE approaches improve business-to-business interactions, while others ensure that the needs of consumers are met with less resources. These were broken down into the global potential energy savings that could be achieved through different subsets of CE approaches applied in the UK as illustrated in Figure 5. CE interventions may be characterised as 'getting more out' and 'putting less in'. Examples of the former include using products longer or more intensely, refurbishment and reuse of products. Examples of the latter include reducing material content of products by way of optimised designs or stronger materials, increasing material production yields, and enhanced recycling. Comparison of regional and temporal variations in the ratio of energy efficiency to energy productivity (Cooper et al., 2017b) indicate that there may be additional untapped potential for energy demand reductions relating to the service that products and energy provide. However, even without this, Cooper et al. (2017a) found that techniques for 'getting more out' have greater potential in the UK than those associated with 'putting less in'.

\section{The international context}

Technical opportunities for the 'deep decarbonisation' of industry have been under active development and appraisal elsewhere in the industrialised world. These have naturally been focused on EI industrial sectors, such as basic materials: iron and steel (Åhman et al., 2016; Arens et al., 2017; Bataille et al., 2018; Leeson et al., 2017; Morfeldt et al., 2015; Napp et al., 2014; Rootzén and Johnsson, 2015; Wesseling et al., 2017), aluminium (Åhman et al., 2016; Bataille et al., 2018; Wesseling et al., 2017), cement (Åhman et al., 2016; Bataille et al., 2018; Hills et al., 2016; Leeson et al., 2017; Li et al., 2013; Napp et al., 2014; Rootzén and Johnsson, 2015; Wesseling et al., 2017); chemicals (Bataille et al., 2018), glass (Bataille et al., 2018; Wesseling et al., 2017) and pulp and paper (Bataille et al., 2018; Leeson et al., 2017; Wesseling et al., 2017). The measures advocated largely reflect those identified in Section 5, including the 'low-hanging fruit' of improved energy efficiency, 'resource efficiency' (i.e. CE interventions), and the use of biofuels and bio-based materials, alongside decarbonised power generation (Lechtenböhmer et al., 2016). In terms of disruptive technologies, the main focus has been on the potential role of industrial CCS (Åhman et al., 2013; Hills et al., 2016; Leeson et al., 2017; Li et al., 2013; Morfeldt et al., 2015; Rootzén and Johnsson, 2015). Rootzén and Johnsson (2015) examined the potential of industrial CCS in EI sectors within a Nordic context, and found that large-scale CCS deployment would result in a significant 'penalty' in terms of both its energy use and additional carbon dioxide emissions. A techno-economic appraisal of CCS in several EI industries by Leeson et al. (2017) found that the 


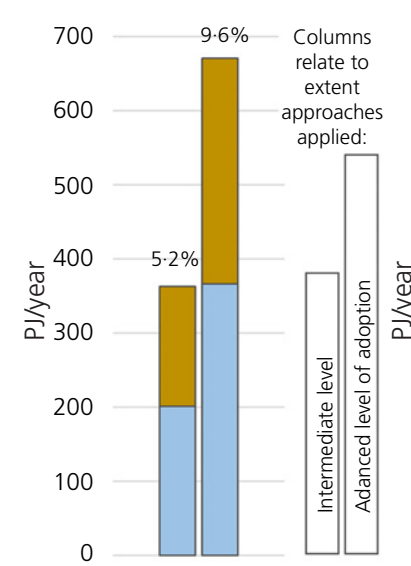

Total for all approaches

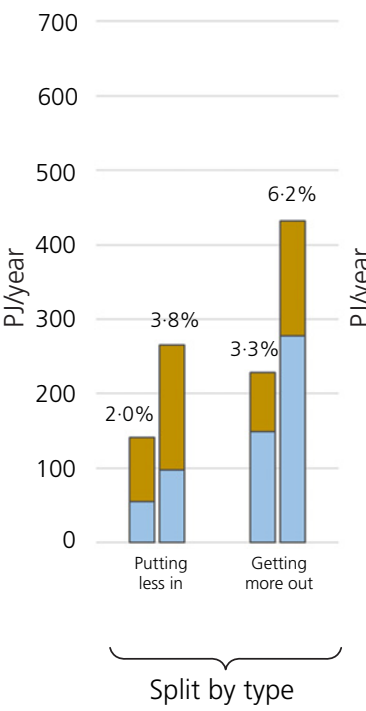

Split by type

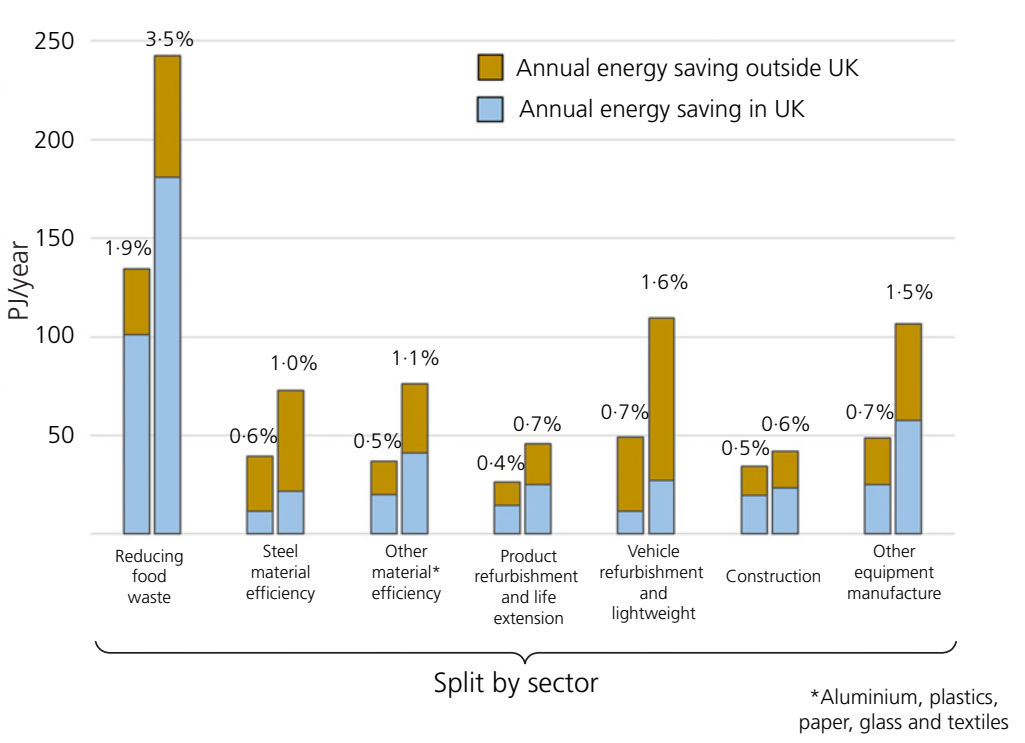

Figure 5. Reduction in energy use possible for the UK through different subsets of CE interventions (data from Cooper et al. (2017a)). Percentages refer to global reduction in energy use due to CE approaches applied in the UK, as a proportion of UK industrial energy use in 2007. Note that the sum of savings for approaches split by type or sector is greater than the total savings for all approaches as some approaches affect the same energy use

main factor influencing cost-reduction measures was the start date of large-scale deployment. Delays in instigating CCS demonstration projects, as in the case of the UK, will prove costly in the long term.

The iron and steel and cement sectors collectively accounted for some $56 \%$ of global industrial carbon dioxide emissions in the recent past (Napp et al., 2014), and have therefore been the subject of a number of international studies. In the iron and steel sector there are various ways in which the processrelated GHG emissions associated with the production of virgin steel can be substantially reduced (Åhman et al., 2016): process-integrated CCS, electrification (or 'electrowinning') and biomethane/hydrogen direct reduced iron (DRI). Morfeldt et al. (2015) used a global energy-economic systems model (ETSAP-TIAM), together with a Scrap Availability Assessment Model, to assess the links between steel demand, recycling rates, and the international availability of scrap. This northern European team (from Belgium, Sweden and the Netherlands) found that energy-efficiency improvements would only secure iron and steel sector decarbonisation out to 2050 if coupled with CCS deployment. In contrast, these coupled models (Morfeldt et al., 2015) indicated that hydrogen-based steel production could prove a major climate change option for virgin material should CCS not be feasible. In a German context, Arens et al. (2017) suggested that efforts to reduce carbon dioxide emissions from the iron and steel sector should focus on incremental improvements in the medium term, because innovative processes (such as hydrogen-based DRI or steel from electrolysis employing carbon dioxide-free electricity) will take decades to develop and deploy. However in the case of the cement sector, Hills et al. (2016) suggest that decarbonisation could be difficult or expensive without CCS. They went on to highlight the need for reducing shut-down times for capture plant construction, which led to both increased overall cost and cumulative carbon dioxide emissions. Li et al. (2013) argue that large-scale demonstration of carbon dioxide capture in the cement sector will require either public financial support or CCU. Nevertheless, Åhman et al. (2016), again from a northern European perspective (Belgium and Sweden), expressed the belief that the radical reductions in GHG emissions beyond 2050 will require disruptive technologies in the steel industry (e.g. electrowinning or the so-called HIsarna concept) or a magnesium- or oxygen-based process with CCS to replace existing cement kilns. Griffin et al. (2016) also examined a number of innovative alternatives for substituting ordinary Portland cement (OPC) on a mass-scale, but noted that it might take a number of years to overcome regulatory barriers and establish new standard regimes and construction codes. 


\section{Concluding remarks: securing a decarbonisation pathway for industry}

A number of opportunities and priorities for industrial decarbonisation and improved resource efficiency in the UK have been articulated. However, the task for both industrial and policy decision makers will be challenging. The aspirations highlighted in the UK government's recent CGS need to be clarified and more clearly elaborated. In order to achieve its commitments under the 2015 Paris Agreement, the UK government should not rely on accounting 'flexibilities' (what the CCC regards as 'banking and borrowing') or reliance on international carbon credits. The joint industry-government Action Plans and forthcoming Sector Deals will have to be delivered in partnership. The technology roadmaps to 2050 exhibit quite large uncertainties, and the attainment of significant falls in GHG emissions over the long term will depend critically on the adoption of a small number of key technologies highlighted above, alongside the decarbonisation of the electricity supply (Griffin et al., 2014, 2016, 2017, 2018). The latter implies the generation of electricity by way of various combinations of fossil-fuelled power plants with coupled CCS/CCU facilities, nuclear power and various renewable energy technologies, principally large-scale wind or solar photovoltaic arrays at a range of geographic scales (Hammond and Pearson, 2017; Lechtenböhmer et al., 2016). CHP plants will also have a role in a number of industrial sectors. Large and complex paper mills, for example, typically take control of their energy supplies by building CHP plants that are more efficient than separate supply of electricity and heat, and thereby reduce GHG emissions and generating costs (Griffin et al., 2018). A number of such CHP plants use biogenic (wood) waste to produce this 'auto-generated' electricity, which is a renewable resource and gives rise to further reductions in GHG emissions. The UK paper sector is consequently the largest user and producer of bioenergy in Europe. Thus, a credible range of technical measures for decarbonisation across the UK economy, and for industry in particular (see e.g. Åhman et al., 2013, 2016; Arens et al., 2017; Bataille et al., 2018; Griffin et al., 2016; Napp et al., 2014; Wesseling et al., 2017), need to be set out. Put 'meat on the bones' of the framework set out in the British government's strategy.

CE interventions have the potential to make significant energy savings that are complementary to other energy-efficiency measures. In order to maximise the benefits from the adoption of CE approaches, they need to be applied widely and consistently (Cooper et al., 2017a, 2017b), reflecting the international nature of supply chains. The actual interventions are varied in their nature and their scope. In general, the CE approaches that exhibit the greatest potential energy savings are those that can either be applied broadly or relate to relatively concentrated flows of goods or services. For example, some options to reduce food waste can be applied to a large proportion of the existing food waste, whereas some of the options to improve resource efficiency in manufacturing or construction are specific to particular processes. This does not negate the value of the approaches that are specific, but indicates that policies with broad applicability may have greater scope to facilitate change. Such measures and policies are often associated with both key users of goods (e.g. construction, retail and public services) and with some of the key materials that are employed (e.g. steel, chemicals, cement, paper, plastics, etc.). There is greater overall scope for energy savings within the UK through $\mathrm{CE}$ interventions that make more effective use of products than through those that make production more resource efficient. However, the potential for each type of approach is significant. Policy measures that encourage the uptake of CE interventions should therefore target both sides of the supply relationship.

Clearly, a range of policy and financial instruments are required in order to implement the UK government's CGS and its associated industrial opportunities. They will need further articulation over the coming months and years. To aid in this process, there is a growing body of international guidance on such instruments to encourage the take-up of industrial decarbonisation measures. Policy approaches will be required to support research, development, demonstration and deployment in order to stimulate near-zero-carbon dioxide basic materials and novel, pre-commercial mitigation technologies in the future, although they may need international agreements, particularly on climate change, to offset the constraints of global, price-competitive markets (Åhman et al., 2016; Bataille et al., 2018; Napp et al., 2014). Decarbonisation options for basic materials processing offer little by way of 'co-benefits' (Åhman et al., 2016), and these technologies often give rise to significant additional costs. Napp et al. (2014) therefore advocated 'carbon pricing', subsidies and other economic instruments to incentivise fuel-switching and low-cost efficiency measures. They also foresaw the need for energy and emissions monitoring systems; something that has been taken up as part of the BEIS SECR proposals (HMG, 2017a). Åhman et al. (2013) also argued in favour of the use of public funds to finance the up-scaling and demonstration of new low-carbon dioxide technologies in order to share the risks. That is perhaps something that is more acceptable in a northern European context than in Britain. In any event, much still needs to be done on both the technology and policy development fronts in order to reduce significantly the carbon dioxide emissions of UK industry by 2050 .

\section{Acknowledgements}

The work reported here forms part of a programme of research at the University of Bath on the technology assessment of 
energy systems and industrial decarbonisation that has been supported by a series of the UK research grants and contracts awarded by various bodies associated with the UK Research and Innovation (UKRI) Energy Programme for which Professor Hammond was the holder. That associated with industrial energy demand and carbon dioxide emissions reduction originally formed a part of the 'core' research programme of the UK Energy Research Centre (UKERC); phase 2, 2009-2014 (under grant NE/G007748/1). This was part of a UKERC flexible funding project titled 'Industrial Energy Use from a Bottom-up Perspective' (for which Professor Hammond was the principal investigator). More recently, the ongoing studies have been supported by the UK Engineering and Physical Sciences Research Council (EPSRC) 'End Use Energy Demand' (EUED) Programme, as part of the Centre for Industrial Energy, Materials and Products (CIE-MAP) (under grant EP/N022645/1). Professor Hammond is one of the four co-directors of CIE-MAP. He was commissioned in 2015 to produce, jointly with several members of his research team, a technical peer review of UK government's 2050 Industrial Decarbonisation Roadmaps. Subsequently, he was engaged in the development of the follow-on Industrial Decarbonisation 'Action Plans' in the areas of bioenergy and 'value chain collaboration' (i.e. CE interventions). Dr Cooper is a research associate working on the CIE-MAP project with a focus on the improvement of energy and material efficiency of the industrial sector.

\section{REFERENCES}

Åhman M, Nikoleris A and Wyns T (2013) Decarbonizing industry: emerging roadmaps point to major need for financing radical innovation. Carbon Management 4(1): 5-7.

Åhman M, Nilsson LJ and Johansson B (2016) Global climate policy and deep decarbonization of energy-intensive industries. Climate Policy 17(5): 634-649.

Arens M, Worrell E, Eichhammer W, Hasanbeigi A and Zhang Q (2017) Pathways to a low-carbon iron and steel industry in the medium-term - the case of Germany. Journal of Cleaner Production 163: 84-98.

Ares E and Hirst D (2015) Paris Climate Change Conference. House of Commons Library, London, UK, Briefing Paper CPB 7393.

Bataille C, Åhman M, Neuhoff K et al. (2018) A review of technology and policy deep decarbonization pathway options for making energy-intensive industry production consistent with the Paris Agreement. Journal of Cleaner Production 187: 960-973.

BEIS (Department for Business, Energy and Industrial Strategy) (2017) Energy Consumption in the UK (ECUK). BEIS, London, UK.

CCC (Committee on Climate Change) (2015) The Fifth Carbon Budget - The Next Step Towards a Low-Carbon Economy. CCC, London, UK.

CCC (2018) An Independent Assessment of the UK's Clean Growth Strategy: From Ambition to Action. CCC, London, UK.

Chen Q, Hammond GP and Norman JB (2016) Energy efficiency potentials: contrasting thermodynamic, technical and economic limits for organic Rankine cycles within UK industry. Applied Energy 164: 984-990.
Climate Change Act 2008. Chapter 27. Her Majesty's Stationery Office, London, UK.

Cooper SJG, Hammond GP and Norman JB (2016) Potential for use of heat rejected from industry in district heating networks, GB perspective. Journal of the Energy Institute 89(1): 57-69.

Cooper SJG, Giesekam J, Hammond GP et al. (2017a) Thermodynamic insights and assessment of the 'circular economy'. Journal of Cleaner Production 162: 1356-1367.

Cooper SJG, Hammond GP and Norman JB (2017b) An empirical assessment of sector-level exergy analysis. Energy Procedia 142: 4050-4055.

Cranston GR and Hammond GP (2012) Carbon footprints in a bipolar, climate-constrained world. Ecological Indicators 16: 91-99.

DECC (Department of Energy and Climate Change) (2011) Planning our Electric Future: A White Paper for Secure, Affordable and Low-Carbon Electricity. The Stationery Office, London, UK.

DECC (2012) CCS Roadmap: Supporting Deployment of Carbon Capture and Storage in the UK. DECC, London, UK.

Dyer $\mathrm{CH}$, Hammond GP, Jones $\mathrm{Cl}$ and McKenna RC (2008) Enabling technologies for industrial energy demand management. Energy Policy 36(12): 4434-4443.

EC (European Commission) (2015) Closing the Loop: An EU Action Plan for the Circular Economy. EC, Brussels, Belgium, COM (2015) 614 final.

EE (Element Energy) (2010) Potential for the Application of CCS to UK Industry and Natural Gas Power Generation. Element Energy, Cambridge, UK (Final Report for the UK Committee on Climate Change).

EMAF (Ellen MacArthur Foundation) (2015) Towards the Circular Economy: Economic and Business Rationale for an Accelerated Transition. EMAF, Cowes, UK.

Griffin PW, Hammond GP and Norman JB (2014) Prospects for emissions reduction in the UK cement sector. Proceedings of the Institution of Civil Engineers - Energy 167(3): 152-161, https://doi.org/ 10.1680/ener.14.00007.

Griffin PW, Hammond GP and Norman JB (2016) Industrial energy use and carbon emissions reduction: a UK perspective. WIREs Energy and Environment 5(6): 684-714.

Griffin PW, Hammond GP and Norman JB (2017) Industrial energy use and carbon emissions reduction in the chemicals sector: a UK perspective. Applied Energy, https://doi.org/10.1016/j.apenergy. 2017.08.010.

Griffin PW, Hammond GP and Norman JB (2018) Industrial decarbonisation of the pulp and paper sector: a UK perspective. Applied Thermal Engineering 134: 52-162.

Hammond GP (2000) Energy, environment and sustainable development: a UK perspective. Transactions of the Institute of Chemical Engineers Part B: Process Safety and Environmental Protection 78(4): 304-323.

Hammond GP (2007) Industrial energy analysis, thermodynamics and sustainability (In memoriam: Willem van Gool). Applied Energy 84(7-8): 675-700.

Hammond G (2013) Briefing: carbon dioxide capture and storage faces a challenging future. Proceedings of the Institution of Civil Engineers - Civil Engineering 166(4): 147.

Hammond GP (2014) Editorial: Progress in energy demand reduction from here to 2050. Proceedings of the Institution of Civil Engineers - Energy 167(3): 89-102, https://doi.org/10.1680/ener. 167.3.89.

Hammond GP and Hazeldine T (2015) Indicative energy technology assessment of advanced rechargeable battery technologies. Applied Energy 138: 559-571. 
Hammond GP and Norman JB (2014) Heat recovery opportunities in UK industry. Applied Energy 116: 387-397.

Hammond GP and Pearson PJG (2017) Realising transition pathways to a low-carbon future (Editorial)'. Proceedings of the Institution of Mechanical Engineers Part A: Journal of Power and Energy 231(6): 435-439.

Hammond GP and Winnett $A B$ (2006) Interdisciplinary perspectives on environmental appraisal and valuation techniques. Proceedings of the Institution of Civil Engineers - Waste and Resource Management 159(3): 117-130.

Hills T, Florin N and Fennell PS (2016) Decarbonising the cement sector: a bottom-up model for optimising carbon capture application in the UK. Journal of Cleaner Production 139: 1351-1361.

HMG (Her Majesty's Government) (2017a) The Clean Growth Strategy: Leading the Way to a Low Carbon Future. Department of Business, Energy and Industrial Strategy (BEIS), London, UK.

HMG (2017b) Industrial Strategy: Building a Britain Fit for the Future. Department of Business, Energy and Industrial Strategy (BEIS), London, UK.

IPCC (Intergovernmental Panel on Climate Change) (2013) Climate Change 2013 - The Physical Science Basis. World Meteorological Office (WMO)/United Nations Environment Programme (UNEP), Geneva, Switzerland.

Lechtenböhmer S, Nilsson LJ, Åhman M and Schneider C (2016) Decarbonising the energy intensive basic materials industry through electrification - implications for future EU electricity demand. Energy 115(3): 1623-1631.

Leeson D, Mac Dowell N, Shah N, Petit C and Fennell PS (2017) A techno-economic analysis and systematic review of carbon capture and storage (CCS) applied to the iron and steel, cement, oil refining and pulp and paper industries, as well as other high purity sources. International Journal of Greenhouse Gas Control 61: 71-84.

Li J, Tharakan P, Macdonald D and Liang X (2013) Technological, economic and financial prospects of carbon dioxide capture in the cement industry. Energy Policy 61: 1377-1387.

Morfeldt J, Nijs W and Silveira S (2015) The impact of climate targets on future steel production - an analysis based on a global energy system model. Journal of Cleaner Production 103: 469-482.

Napp TA, Gambhir A, Hills TP, Florin N and Fennell PS (2014) A review of the technologies, economics and policy instruments for decarbonising energy-intensive manufacturing industries. Renewable and Sustainable Energy Reviews 30: 616-640.

ONS (Office for National Statistics) (2017) UK Environmental Accounts: 2017. ONS, London, UK.

Roddy DJ (2012) Development of a $\mathrm{CO}_{2}$ network for industrial emissions. Applied Energy 91(1): 459-465.

Rootzén J and Johnsson $\mathrm{F}(2015) \mathrm{CO}_{2}$ emissions abatement in the Nordic carbon-intensive industry - an end-game in sight? Energy 80: 715-730.

Van Gool W (1975) Energy research and development program for the Netherlands. Proceedings of the Energy Technology II Conference, Washington DC, USA, pp. 135-142.

Wesseling JH, Lechtenböhmer S, Åhman M et al. (2017) The transition of energy intensive processing industries towards deep decarbonization: characteristics and implications for future research. Renewable and Sustainable Energy Reviews 79: $1303-1313$.

\section{How can you contribute?}

To discuss this paper, please email up to 500 words to the editor at journals@ice.org.uk. Your contribution will be forwarded to the author(s) for a reply and, if considered appropriate by the editorial board, it will be published as discussion in a future issue of the journal.

Proceedings journals rely entirely on contributions from the civil engineering profession (and allied disciplines).

Information about how to submit your paper online is available at www.icevirtuallibrary.com/page/authors, where you will also find detailed author guidelines. 